\title{
Combined First trimester Maternal Platelets Indices and Uterine Artery Doppler in Prediction of Pre-eclampsia in the Primigravidae
}

\author{
Muhammad Ahmad Aboulfotouh Ebraheem ${ }^{1}$,* M.B.B.Ch., Mohamed Mohamed Gebreel ${ }^{2}$ MD. and \\ Muhamed Ahmed Abdelmoaty ${ }^{2}$ MD.
}

\author{
* Corresponding Author: \\ Muhammad Ahmad Aboulfotouh \\ dr.m7d17@gmail.com
}

\section{Received for publication July 01, 2021; Accepted August 31, 2021; Published online August 31, 2021.}

Copyright The Authors published by Al-Azhar University, Faculty of Medicine, Cairo, Egypt. Users have the right to read, download, copy, distribute, print, search, or link to the full texts of articles under the following conditions: Creative Commons Attribution-Share Alike 4.0 International Public License (CC $B Y-S A$ 4.0).

doi: 10.21608/aimj.2021.82382.1514

${ }^{I}$ Department of Obstetrics and Gynecology, Sharm El-Sheikh International Hospital, Egypt.

${ }^{2}$ Department of Obstetrics and Gynecology, Faculty of Medicine, AlAzhar University, Cairo, Egypt.

\begin{abstract}
Background: Pre-eclampsia is a heterogeneous disease influencing various systems of the body and commonly accompanied by morbidity and death. Early pre-eclampsia prognostication would decrease this accompanied morbidity and death as it will give the chance for common motherly and fetal surveillance and utilization of prophylactic operations. Objective: To assess whether the use of maternal platelet indices combined with uterine artery Doppler during 1st trimester could enhance the prediction of later pre-eclampsia in primigravidae women.

Patients and Methods: This prospective study includes 30 pregnant women selected from Obstetrics and Gynecology department, Al-Azhar university hospitals. All the selected pregnant women were primigravidae in 1 st trimester at the start of the study. The study was conducted from October 2020 to May 2021.

Results: The uterine artery Doppler indices in prognostication of Preeclampsia were: sensitivity $85.7 \%$, specificity $91.3 \%$, NPV $95.5 \%$, and PPV $75 \%$ with an accuracy of $90 \%$. The maternal platelets indices in prediction of Pre-eclampsia were: sensitivity $57.14 \%$, specificity $91.3 \%$, NPV $87.5 \%$, and PPV $66.67 \%$ with an accuracy of $83.3 \%$. The combined uterine artery Doppler and maternal platelets indices in prognostication of Pre-eclampsia were: sensitivity $85.7 \%$, specificity $100 \%$, NPV $95.8 \%$, and PPV $100 \%$ with an accuracy of $96.7 \%$.

Conclusion: In our study, we figured out that the maternal platelets indices in combination with the Doppler assessment of the uterine artery as reliable screening tests to enhance the prognostication of Preeclampsia in primigravidae at the 1 st trimester.
\end{abstract}

Keywords: platelets; Doppler; indices; Preeclampsia.
Disclosure: The authors have no financial interest to declare in relation to the content of this article. The Article Processing Charge was paid for by the authors.

Authorship: All authors have a substantial contribution to the article.

\section{INTRODUCTION}

Pre-eclampsia (PE) is a severe gestation hypertensive complication with a worldwide incidence of $2-10 \%$. It is believed that it one of chief causes of maternal and fetal morbidities and even mortalities 1 .

Maternal complications of PE include severe high blood pressure, liver \& renal failures, coagulopathy, HELLP syndrome and Eclampsia. Perinatal morbidities have been greatly increased with $\mathrm{PE}$ due to associated intra-uterine growing limit and pre-mature delivery ${ }^{2}$. Also, maternal deaths with PE and Eclampsia are estimated to be $13 \%$ of total maternal deaths ${ }^{3}$.

As the ultimate goal of antenatal care is to recognize high-risk pregnancies and provide proper prophylactic treatment, so it is a must to find a reliable and effective way for predicting PE as early that we can decrease the incidence of maternal and fetal mortality and morbidity ${ }^{4}$.
The development of PE is believed to be a result of reduced trophoblastic invasions of maternal spiral arteries that is supposed to convert the narrow muscular vessels into wide non-muscular ducts. This alteration ensures that the placental blood flow is maintained under any circumstances ${ }^{5}$.

This physiological trophoblastic invasion can be reflected clinically with the aid of Doppler ultrasound investigations as impedance to flow in the uterine artery (UtA) reduces from 6 th to $24^{\text {th }}$ weeks of pregnancy and continues unchanged thereafter ${ }^{6}$.

Therefore, abnormal UtA Doppler waveforms mirror elevated impedance in uterine circulations. The raised impedance is believed to be happening as a result of the failures of the trophoblastic invasion of maternal spiral arteries ${ }^{7}$.

UtA Doppler waveforms indices at 12th-16th weeks are the best noninvasive monitoring tests existing for early detection of Pre-eclampsia, so the struggle index, the pulsatility index (PI), and the persistent 
notching in UtA Doppler waveforms are dependable monitoring tests for $\mathrm{PE}^{8}$.

Also, it was proposed that the variations in coagulation and fibrinolysis have a function in the $\mathrm{PE}$ pathogenesis. The biomarkers of platelet activations involving platelet count (PC), platelet distribution width (PDW), mean platelet volume (MPV) and plateletcrit (PCT). The elevation in the MPV and PDW is detected in PE. The MPV and PDW have a significant association with raised BP. But the PC and PCT do not show a significant correlation with $\mathrm{PE}^{9}$.

Therefore, use of the UtA Doppler in combination with bio-markers seems to be a hopeful field of clinical studies about PE ${ }^{10}$.

Our study designed to assess the use of UtA Doppler study combined with the maternal platelet indices during the $1^{\text {st }}$ trimester in predication of development of PE later in pregnancy.

\section{PATIENTS AND METHODS}

This prospective study included 30 pregnant women primigravidae in their $1^{\text {st }}$ trimester. All cases were selected from Obstetrics and Gynecology Department, Al-Hussein Hospital, Al-Azhar University. The study had been conducted from October 2020 to May 2021.

The current study was approved by Institution Research Board (IRB) of faculty of medicine Al Azhar University. Informed consent was attained from all participants with full clarification of risks and benefits of the study. Confidentiality and personal privacy were appreciated in all steps of the study.

Patients were enrolled in the study according to the following criteria; Primigravidae women with a singleton gestation in the $1^{\text {st }}$ trimester.

Patients were excluded from the study according to the following criteria: Chronic hypertension, Multiparaea, multiple pregnancies, molar pregnancy, chronic diseases and abnormalities of the fetus.

The whole number of cases was exposed to:

1. Complete history taking: Personal, general, obstetric, medical, surgical and family history.

2. Examination: general and local examination.

3. Laboratory Investigations: - A complete blood count had been performed via BECKMAN COULTER DxH520-2019 device for the estimation of platelets indices (PC, MPV, PDW) using kits from BIO RADIDiaMed. Urine analysis had been also done to detect proteinuria. Routine laboratory investigations (Blood group, Rhesus factor, random blood sugar, liver and kidney functions tests) were also conducted.

4. Doppler:(figure 1:a \& b)

Once a viable intrauterine pregnancy had been confirmed, the UtA Doppler assessment was performed on a GE S5 LOGIQ P7 US unit via a trans-abdominal method. To confirm reliability of the findings, the investigator was the only one executed the scans and the US machine was serviced and regularly calibrated. The sample gate was located over the whole artery diameter and pulsed wave Doppler was utilized to get 3 successive UtA waves and the PI was assessed jointly. The presence of the UtA notching and a PI $>1.5$ throughout the 1 st trimester was considered as an indication of elevated vascular resistances in the placental bed. The Doppler evaluation of the UtA was repeated at monthly intervals.
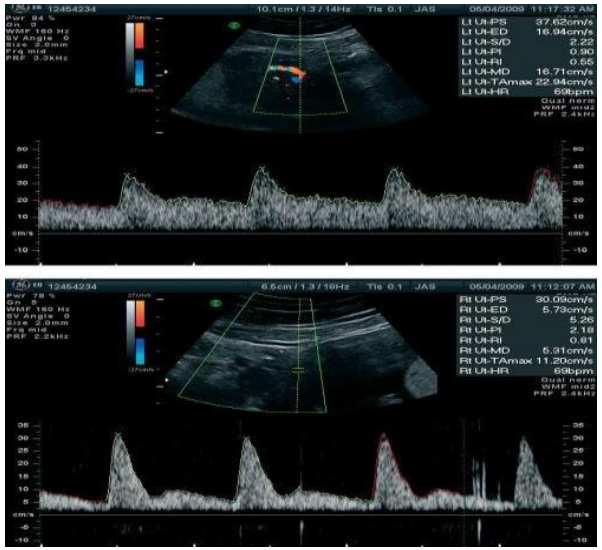

Fig (1): (a) ordinary 1st-trimester UtA Doppler waveforms and (b) 1st-trimester high-resistance UtA Doppler with a diastolic notch.

The follow up:

Women developed PE had been admitted to the mentioned hospital whereas cases of PE with severe features received intravenous medications to control blood pressure and prevent seizures till delivery of the fetus was possible. Cases of PE without severe features less than 37 weeks, close monitoring for the female and her fetus was done till delivery with investigations to assess maternal platelet counts, liver and kidney functions, and urinary protein level. Investigations for the fetus comprised US, monitor of heart rate, evaluation of fetal growing, and amniotic fluid evaluation.

Study Hypothesis: UtA Doppler study combined with maternal platelet indices during $1^{\text {st }}$ trimester could be useful tools to prognostic the development of PE.

Null Hypothesis was that there is no role for $1^{\text {st }}$ trimester $1^{\text {st }}$ UtA Doppler study combined with maternal platelet indices in prediction of $\mathrm{PE}$ in primigravidae women.

Statistical Analysis: The collected Data analyzed via the windows-based IBM-SPSS-20.0. Regarding to the kind of data qualitative presented as numbers and percentages, quantitative continues group presented by mean $\pm \mathrm{SD}$, the subsequent tests have been utilized to test changes for significance; association by Pearson's test or Spearman's. P-value was considered as significant at $<0.05$ for \& highly significant at $<0.001$. 


\section{RESULTS}

A significant change was found among the two studied groups in regard to MPV, PDW and PCT in Table (1).

\begin{tabular}{|c|c|c|c|c|}
\hline & $\begin{array}{l}\text { Preeclampsia } \\
\quad(n=7)\end{array}$ & $\begin{array}{l}\text { Normotensive } \\
\quad(n=23)\end{array}$ & $\mathrm{t}$ & $\mathrm{P}$ \\
\hline $\begin{array}{l}\operatorname{PLT}\left(\times 10^{3} /\right) \\
\text { Mean } \pm \text { SD }\end{array}$ & $237.54 \pm 57.76$ & $252.31 \pm 45.14$ & .711 & .483 \\
\hline $\begin{array}{l}\text { MPV (fL) } \\
\text { Mean } \pm \text { SD }\end{array}$ & $9.72 \pm 0.831$ & $7.88 \pm 0.95$ & 4.61 & .000 \\
\hline $\begin{array}{l}\text { PDW (\%) } \\
\text { Mean } \pm \text { SD }\end{array}$ & $17.13 \pm 1.02$ & $13.74 \pm 1.48$ & 5.63 & .000 \\
\hline $\begin{array}{l}\text { PCT }(\%) \\
\text { Mean } \pm \text { SD }\end{array}$ & $20.11 \pm 1.55$ & $22.39 \pm 2.1$ & 2.65 & .013 \\
\hline
\end{tabular}

Table 1: Platelet indices between the studied groups

PLT: platelet counts MPV: mean platelet volume PDW: platelet distributing width PCT: plateletcrit

Table (2) shows that RI and PI were significantly high in PE-group in comparison with the significantly more frequent in $\mathrm{PE}$ group that normotensive-group. Moreover, diastolic notch was normotensive-group.

\begin{tabular}{|c|c|c|c|c||}
\hline & $\begin{array}{c}\text { Preeclampsia } \\
(\mathrm{n}=23)\end{array}$ & $\begin{array}{c}\text { Normotensive } \\
(\mathrm{n}=23)\end{array}$ & $\mathrm{t}$ & $\mathrm{P}$ \\
\hline $\begin{array}{c}\text { Resistance index } \\
\text { Mean } \pm \text { SD }\end{array}$ & $0.726 \pm 0.099$ & $0.573 \pm 0.102$ & 3.49 & .001 \\
\hline $\begin{array}{c}\text { Pulsatility index } \\
\text { Mean } \pm \text { SD }\end{array}$ & $1.51 \pm 0.359$ & $0.935 \pm 0.268$ & 4.59 & .000 \\
\hline Diastolic notch & $6(85.7 \%)$ & $2(8.7 \%)$ & $\square^{2} 16.3$ & .000 \\
\hline
\end{tabular}

Table 2: UtA Doppler indices between the studied groups

Table (3) shows there is a significant difference between the groups regarding GA only.

\begin{tabular}{|c|c|c|c|c||}
\hline & $\begin{array}{c}\text { Preeclampsia } \\
(\mathrm{n}=7)\end{array}$ & $\begin{array}{c}\text { Normotensive } \\
(\mathrm{n}=23)\end{array}$ & $\mathrm{t}$ & $\mathrm{p}$ \\
\hline $\begin{array}{c}\text { GA (weeks) } \\
\text { Mean } \pm \text { SD }\end{array}$ & $35.44 \pm 0.927$ & $37.6 \pm 0.629$ & 7.11 & .000 \\
\hline $\begin{array}{c}\text { Birth weight (kg)Mean } \\
\pm \text { SD }\end{array}$ & $2.84 \pm 0.435$ & $3.02 \pm 0.314$ & 1.21 & .749 \\
\hline $\begin{array}{c}\text { Apgar at 1 min } \\
\text { Mean } \pm \text { SD }\end{array}$ & $6.73 \pm 1.65$ & $7.11 \pm 0.964$ & .768 & .754 \\
\hline $\begin{array}{c}\text { Apgar at 5 min } \\
\text { Mean } \pm \text { SD }\end{array}$ & $9.71 \pm 0.499$ & $9.86 \pm 1.21$ & .317 & .459 \\
\hline
\end{tabular}

Table 3: Neonatal outcomes between the studied groups

The UtA Doppler indices in prognostication of PE were: sensitivity $85.7 \%$, specificity $91.3 \%$, NPV $95.5 \%$ and PPV $75 \%$ with accuracy of $90 \%$. Table (4) 


\begin{tabular}{|c|c|c|c|c|c|c|}
\hline \multirow[t]{2}{*}{ Doppler } & \multicolumn{2}{|c|}{$\begin{array}{l}\text { Preeclampsia } \\
\quad(n=7)\end{array}$} & \multicolumn{2}{|c|}{$\begin{array}{l}\text { Normotensive } \\
\quad(n=23)\end{array}$} & \multirow[t]{2}{*}{ Total } & \multirow[t]{2}{*}{$\mathrm{P}$} \\
\hline & $\mathrm{N}$ & $\%$ & $\mathrm{~N}$ & $\%$ & & \\
\hline Abnormal & 6 & $57.1 \%$ & 2 & 8.7 & 8 & \multirow{2}{*}{.000} \\
\hline Normal & 1 & $42.9 \%$ & 21 & $91.3 \%$ & 22 & \\
\hline \multicolumn{2}{|c|}{ Statistic } & \multicolumn{2}{|c|}{ Value } & \multicolumn{3}{|c|}{$95 \% \mathrm{CI}$} \\
\hline \multicolumn{2}{|c|}{ Sensitivity } & \multicolumn{2}{|c|}{$85.71 \%$} & \multicolumn{3}{|c|}{$42.13 \%-99.64 \%$} \\
\hline \multicolumn{2}{|c|}{ Specificity } & \multicolumn{2}{|c|}{$91.3 \%$} & \multicolumn{3}{|c|}{$71.96 \%-98.93 \%$} \\
\hline \multicolumn{2}{|c|}{ Positive Predictive Value (PPV) } & \multicolumn{2}{|c|}{$75 \%$} & \multicolumn{3}{|c|}{$43.54 \%-92.11 \%$} \\
\hline \multicolumn{2}{|c|}{ Negative Predictive Value (NPV) } & \multicolumn{2}{|c|}{$95.45 \%$} & \multicolumn{3}{|c|}{$77.3 \%-99.23 \%$} \\
\hline \multicolumn{2}{|c|}{ Accuracy } & \multicolumn{2}{|c|}{$90 \%$} & \multicolumn{3}{|c|}{$73.47 \%-97.89 \%$} \\
\hline
\end{tabular}

Table 4: UtA Doppler indices in relation to PE

The platelets indices in prognostication of $\mathrm{PE}$ were: sensitivity $57.14 \%$, specificity $91.3 \%$, NPV

\begin{tabular}{|c|c|c|c|c|c|c|}
\hline \multirow[t]{2}{*}{ PLT } & \multicolumn{2}{|c|}{$\begin{array}{l}\text { Preeclampsia } \\
(\mathrm{n}=7)\end{array}$} & \multicolumn{2}{|c|}{$\begin{array}{l}\text { Normotensive } \\
\quad(n=23)\end{array}$} & \multirow[t]{2}{*}{ Total } & \multirow[t]{2}{*}{$\mathrm{P}$} \\
\hline & $\mathrm{N}$ & $\%$ & $\mathrm{~N}$ & $\%$ & & \\
\hline Abnormal & 4 & $57.1 \%$ & 2 & 8.7 & 6 & \multirow{2}{*}{.005} \\
\hline Normal & 3 & $42.9 \%$ & 21 & $91.3 \%$ & 24 & \\
\hline \multicolumn{2}{|c|}{ Statistic } & \multicolumn{2}{|r|}{ Value } & \multicolumn{3}{|c|}{$\begin{array}{l}95 \% \\
\text { CI }\end{array}$} \\
\hline \multicolumn{2}{|c|}{ Sensitivity } & \multicolumn{2}{|c|}{$57.14 \%$} & \multicolumn{3}{|c|}{$18.41 \%-90.1 \%$} \\
\hline \multicolumn{2}{|c|}{ Specificity } & \multicolumn{2}{|r|}{$91.3 \%$} & \multicolumn{3}{|c|}{$71.96 \%-98.93 \%$} \\
\hline \multicolumn{2}{|c|}{ Positive Predictive Value (PPV) } & \multicolumn{2}{|c|}{$66.67 \%$} & \multicolumn{3}{|c|}{$31.47 \%-89.7 \%$} \\
\hline \multicolumn{2}{|c|}{ Negative Predictive Value (NPV) } & \multicolumn{2}{|r|}{$87.5 \%$} & \multicolumn{3}{|c|}{$74.67 \%-94.32 \%$} \\
\hline \multicolumn{2}{|c|}{ Accuracy } & \multicolumn{2}{|c|}{$83.33 \%$} & \multicolumn{3}{|c|}{$65.28 \%-94.36 \%$} \\
\hline
\end{tabular}

Table 5: PLT indices in relation to PE

The combined UtA Doppler and PLT indices in prognostication of PE were sensitivity $85.7 \%$,
$87.5 \%$ and PPV $66.67 \%$ with accuracy of $83.3 \%$. Table (5)

specificity $100 \%$, NPV $95.8 \%$ and PPV $100 \%$ with accuracy of $96.7 \%$. Table (6)

\begin{tabular}{|c|c|c|c|c|c|c|}
\hline & \multicolumn{2}{|c|}{$\begin{array}{l}\text { Preeclampsia } \\
(\mathrm{n}=7)\end{array}$} & \multicolumn{2}{|c|}{$\begin{array}{l}\text { Normotensive } \\
(\mathrm{n}=23)\end{array}$} & \multirow[t]{2}{*}{ Total } & \multirow[t]{2}{*}{$\mathrm{P}$} \\
\hline & $\mathrm{N}$ & $\%$ & $\mathrm{~N}$ & $\%$ & & \\
\hline Abnormal & 6 & $85.7 \%$ & 0 & -- & 6 & \multirow{2}{*}{.000} \\
\hline Normal & 1 & $14.3 \%$ & 23 & $100 \%$ & 24 & \\
\hline \multicolumn{2}{|c|}{ Statistic } & \multicolumn{2}{|c|}{ Value } & \multicolumn{3}{|c|}{$95 \% \mathrm{CI}$} \\
\hline \multicolumn{2}{|c|}{ Sensitivity } & \multicolumn{2}{|c|}{$85.71 \%$} & \multicolumn{3}{|c|}{$42.13 \%-99.64 \%$} \\
\hline \multicolumn{2}{|c|}{ Specificity } & \multicolumn{2}{|c|}{$100 \%$} & \multicolumn{3}{|c|}{$85.18 \%-100 \%$} \\
\hline \multicolumn{2}{|c|}{ Positive Predictive Value (PPV) } & \multicolumn{2}{|c|}{$100 \%$} & \multicolumn{3}{|c|}{--} \\
\hline \multicolumn{2}{|c|}{ Negative Predictive Value (NPV) } & \multicolumn{2}{|c|}{$95.83 \%$} & \multicolumn{3}{|c|}{$78.93 \%-99.3 \%$} \\
\hline \multicolumn{2}{|c|}{ Accuracy } & \multicolumn{2}{|c|}{$96.67 \%$} & \multicolumn{3}{|c|}{$82.78 \%-99.92 \%$} \\
\hline
\end{tabular}

Table 6: PLT indices in relation to PE 


\section{DISCUSSION}

Many researches revealed that Doppler ultrasonography is one of the finest prognosticators of PE. The assessment of platelet indices is simple, economical and fasttechnique that was suitable for monitoring and early prognostication of $\mathrm{PE}$ in addition to its significance in diagnosing and evaluating disorder severity. Reduction of PC with rise MPV and PDW were requested early PE markers ${ }^{11}$.

Anomalous UtA Doppler blood flowing and anomalous PI are both connected to the etiological path-ways of PE and combined might progress prognostication of the disorder in comparison to separate usages ${ }^{12}$.

In this study we aimed to know if we can use the maternal platelets indices in combination with the Doppler assessment of the uterine artery as reliable screening tests to enhance the prognostication of Preeclampsia in primigravidae at the $1^{\text {st }}$-trimester.

This prospective study was performed at the Obstetrics and Gynecology Department, AlHussein Hospital, Al-Azhar University on 30 pregnant women visiting antenatal clinics and/or admitted in motherhood wards.

A significant change was found among the two studied groups in regard to MPV, PDW and PCT. We found that RI and PI were significantly higher in pre-eclampsia-group than normotensive-group. Moreover, diastolic notch was significantly more frequent in preeclampsia group than normotensivegroup.

A significant change was found among the study groups regarding GA only. While there's no significant difference regarding birth mass, Apgar at $1 \mathrm{~min}$ and $5 \mathrm{~min}$.

The UtA Doppler indices in prognostication of PE were: sensitivity $85.7 \%$, specificity $91.3 \%$, NPV $95.5 \%$ and PPV $75 \%$ with accuracy of $90 \%$.

Abdel Razik et al., ${ }^{13}$ reported an anomalous Doppler was exist in 80 gravid of whom 44 patients $(55 \%)$ had anomalous PI whereas ordinary Doppler was exist in 190 gravid of whom 13 patients $(6.8 \%)$ had anomalous PI. It showed a significant positive correlation amongst anomalous UtA Doppler and raised MPV and PDW (P-value<0.001).

Razavi et al., ${ }^{14}$ reported that seven out of 37 women with PE had normal Doppler (7.7\%) and 30 were those who had abnormal Doppler (50.8\%). A significant change was found among the cases with ordinary and anomalous Doppler sonography (Pvalue $=0.001)$. Chi-square testing give a nonsignificant variance among severity of preeclampsia in cases with ordinary and non- ordinary Doppler sonography (P-value=0.06). The sensitivity of Doppler ultra-sonography in detecting early, late onsets and severe preeclampsia was $73.3 \%, 62.5 \%$, and $100 \%$, respectively. The specificity of Doppler ultrasonography in detecting early-, late-onsets and severe pre-eclampsia was $64.4 \%, 66.1 \%$, and $74.3 \%$, correspondingly.

Salem \& Ammar, ${ }^{15}$ reported that the mean PI of the uterine artery at 11-13-wks' pregnancy revealed a high significant change among preeclamptic $(2.4 \pm 0.2)$ and ordinary controls $(1.4 \pm$ $0.4)$. The optimum cutoff value of PI from the ROC curve was $\geq 1.69$, gave sensitivity of $100 \%$, specificity of $70 \%$, PPV of $27 \%$, NPV of $100 \%$ and an accuracy of $73 \%$. The PLT indices in prediction of PE sensitivity were $57.14 \%$, specificity was $91.3 \%$, NPV was $87.5 \%$ and PPV was $66.67 \%$ with accuracy of $83.3 \%$.

Nooh \& Abdeldayem, ${ }^{16}$ showed comparing among variations in PC, MPV and PDW in the 3 studied groups. Excepting a few cases in the group of PE with severe characteristics who developed thrombocytopenia, contributors in all groups had an ordinary PC, but it revealed nonstop reduction over the course of gestation between 24 and 28 wks pregnancy forward. This alteration was more noticeable in PE with no severe characteristics than normotensive gestation and in PE with severe characteristics than $\mathrm{PE}$ with no severe characteristics $(p=0.00)$. Variations in PI were prognostic of PE developments with onset of PE diagnosing at 30 and 32-wks pregnancy. As these variations in cases with PE preceded development of disease by 2 to 8 -wks, In comparison to baseline values, MPV and PDW in contributors in studied groups revealed unceasing rise over the gestation course between 24 and 28 -wks pregnancy forwards. This alteration was more noticeable in PE with no severe characteristics than normotensive gestation and in PE with severe characteristics than $\mathrm{PE}$ with no severe characteristics (p-value $=0.00)$.

Nooh \& Abdeldayem, ${ }^{16}$ reported that ROC curve analysis of variations of PDW value at 24 and 28wks pregnancy give a PDW> 19.9 as optimum cutoff for the prognostication of PE development. This cut-off level had an AUC of 0.980 (95\% CI: 0.964 - 1.000), a sensitivity of $96.3 \%$ and a specificity of $91.3 \%$ for prognostication of PE progress. Women with PDW > 19.9 at 24 and 28wks pregnancy were more than 13 -fold at risk of PE progress (RR: 13.36; 95\% CI: 3.5 - 50.96).

As well, in females with PE, PDW was found to have a positive association with MAP, and PDW rise was proportional to the rise in MAP $(r=$ -0.902 ; $p$-value $=0.000$ ); making PDW the finest possible biomarker for predicting severity of high blood pressure. However, Yang et al., ${ }^{17}$ recognized a PDW value of $>13.5$ as the optimum cutoff level for the prognostication of PE severity. They found that this value had an AUC of 0.74 , a sensitivity of $72 \%$ and a specificity of $71 \%$. As well, they concluded that only PDW had a significant association with MAP $(r=0.231$, p-value $=0.011)$ and, consequently, theyreported that PDW was the best PE biomarker.

Similarly, Freitas et al., ${ }^{18}$ found a PDW value of $>18.3$ as the best cutoff level for the predicting PE. They found that this value has an AUC of 0.77 
(95\% CI: $0.66-0.85$ ), a sensitivity of $55.17 \%$ and a specificity of $86.21 \%$. As well, they concluded that only PDW had a significant association with $\operatorname{MAP}(\mathrm{r}=0.231, \mathrm{p}=0.011)$.

The combined uterine artery Doppler study and PLT indices in prognostication of PE were sensitivity $85.7 \%$, specificity $100 \%$, NPV $95.8 \%$ and PPV $100 \%$ with accuracy of $96.7 \%$.

Abdel Razik et al., ${ }^{13}$ showed that in accordance to the findings of Doppler US and PI gravid were separated into 4 groups: GI: anomalous Doppler + anomalous indices; GII: anomalous Doppler + ordinary indices; GIII: ordinary Doppler + anomalous indices and GIV: ordinary Doppler + ordinary indices (controls). It revealed that cases in GI (anomalous Doppler + anomalous indices) have significant high occurrence of severe PE (p-value < 0.001). In contrast, an ordinary Doppler study in most patients indicates normal gestation if accompanying with anomalous platelet (GIII, 84.6\%) or ordinary platelet (GIV, 98.9\%).

In Jain et al., ${ }^{19}$ cases with PE were more expected to have significant reduction in platelets count, rise in PDW and MPV and that these variations could be detected at an early pregnancy age than significant increase in BP could be detected. They reported that approximation of PI could be taken in to consideration as an early, easy and economical method in the prognostication and evaluation of PE severity.

In Nooh \& Abdeldayem, ${ }^{16}$ the PC was lessening whereas MPV and PDW were growing as PE developed and these variations precede progress of PE by $2-8$-wks making it the optimum biomarker for JUST ACCEPTED detecting PE.

Freitas et al., ${ }^{18}$ aim was to study whether PC, MPV, PDW and plateletcrit (PCT) can expect sever form of PE. They studied the ROC curve for each variable and revealed that the parameters have steady diagnosing significance, excepting PCT that was regarded as bad for this aim.

Yang et al., ${ }^{17}$ revealed that in the ROC curve analysis, the AUC of the PDW to expect severe PE was 0.74 . Whereas Doğan et al., ${ }^{12}$ proposed that the growing platelet turnover in PE reasons a reduction in the PC, a rise of MPV values and particularly a reduction in PC/MPV ratio pointing that these features can has a significant function in expecting the risk of PE while they have no function on prediction of the PE severity.

AlSheeha et al., ${ }^{20}$ utilized the ROC curve to find validity of platelets indices in PE prediction and revealed that PC $<248.010 \times 10^{3} / \mu \mathrm{L}$ and and PC to MPV ratio 31.2 are valid prognosticators of PE.

\section{CONCLUSION}

In our study we figured out that the maternal platelets indices in combination with the Doppler assessment of the UtA as reliable screening tests to enhance the prognostication of $\mathrm{PE}$ in primigravidae at the $1^{\text {st }}$-trimester.
Conflict of interest statement: The authors declared that there were NO conflicts of Interest.

Disclosure: The authors have no financial interest to declare in relation to the content of this article.

\section{REFERENCES}

1. Satish S. Int J Reprod Contracept Obstet Gynecol. 2019; 8(4):1317-21.

2. Sibai B, Dekker G and Kupferminc M. Preeclampsia. Lancet. 2005; 365:785 - 99.

3. ACOG Committee on Obstetric Practice. Practice bulletin 33: diagnosis and management of preeclampsia and eclampsia. Obstet Gynecol. 2002; 99(1):159-67.

4. Abd El-Aal NK, El-Halaby AE and Taie AH. Combined second trimester maternal serum $\alpha$ fetoprotein and uterine artery Doppler in the prediction of pre-eclampsia. Menoufia Med J 2019;32:430-5

5. Duckitt $\mathrm{K}$ and Harrington D. Risk factors for pre - eclampsia at antenatal booking: a systematic review of controlled studies. BMJ. 2005; $330: 565$.

6. Alicia $\mathrm{M}$ and Lapidus MD. Effects of preeclampsia on mother, fetus, and child. Obgyn Net. 2011; 1-3.

7. Poon LC, Staboulidou I, Maiz N, et al. Hypertensive disordersin pregnancy: screening by uterine artery Doppler at 11-13 weeks. Ultrasound Obstet Gynecol.2009; 34(2):142-8.

8. Neravi A. Int $J$ Reprod Contracept Obstet Gynecol. 2018 Aug;7(8):3162-7.

9. Nitesh T, Kanika S, Mukta P, et al. Hematol Transfus Cell Ther. 2019; 41(2): 129-33.

10. Audibert F, Boucoiran I, An N, et al. Screening for preeclampsia using fi rst-trimester serum markers and uterine artery Doppler in nulliparous women. Am J Obstet Gynecol. 2010; 203:383.e1-8.

11. N R, A., Jayalakshmi, L., \& S D, K. D. Study of Mean Platelet Volume In Gestational Hypertension And Normal Pregnancy. International Journal of Biomedical Research. 2015; 6(6), 366 https://doi.org/10.7439/ijbr.v6i6.2097

12. Doğan K., Guraslan H., Senturk M. B., et al. Can Platelet Count and Platelet Indices Predict the Risk and the Prognosis of Preeclampsia? Hypertension in Pregnancy. 2015; $34(4), \quad 434-42$ https://doi.org/10.3109/10641955.2015.1060244 
13. Abdel Razik, M., Mostafa, A., Taha, S., et al. Combined Doppler ultrasound and platelet indices for prediction of preeclampsia in highrisk pregnancies. The Journal of MaternalFetal \& Neonatal Medicine. 2019; 32(24), 4128-32.

14. Razavi M., Rashidi F, Farzaneh J, et al. The role of uterine artery Doppler ultrasound in the second trimester in predicting the incidence of early, late and sever preeclampsia. International Journal of Pediatrics. 2019; 0(0), 9405- 11.

https://doi.org/10.22038/ijp.2019.37066.3229

15. Salem M. A. A., \& Ammar I. M. M. FirstTrimester Uterine Artery Pulsatility Indexand Maternal Serum PAPP-A and PlGF in Prediction of Preeclampsia in Primigravida. The Journal of Obstetrics and Gynecology of India. 2018; 68(3), 192-6. https://doi.org/10.1007/s13224-017-1012-5
16. Nooh, A. M., \& Abdeldayem, H. M. Changes in Platelet Indices during Pregnancy as Potential Markers for Prediction of Preeclampsia Development. Open Journal of Obstetrics and Gynecology. 2015; 05(12), 703-712. https://doi.org/10.4236/ojog.2015.512099

17. Yang S. W., Cho S. H., Kwon H. S., et al. Significance of the PDW as a severity marker for the development of preeclampsia. European Journal of Obstetrics \& Gynecology and Reproductive Biology. 2014; 175, 107-11. https://doi.org/10.1016/j.ejogrb.2013.12.036

18. Freitas L. G., Alpoim P. N., Komatsuzaki F., Carvalho M. das G., \& Dusse L. M. S. Preeclampsia: are platelet count and indices useful for its prognostic? Hematology (Amsterdam, Netherlands). 2013,18(6), 360364.

https://doi.org/10.1179/1607845413Y.0000000 $\underline{098}$

19. Jain R., Soni M., Choudhary R., et al. Predictive Value of Platelet Indices in Development of Preeclampsia. Journal of South Asian Federation of Obstetrics and Gynaecology. 2012; 4(1), 17-21. https://doi.org/10.5005/jpjournals-10006-1164

20. AlSheeha M. A., Alaboudi R. S., Alghasham M. A., Iqbal J., \& Adam I. Platelet count and platelet indices in women with preeclampsia. Vascular Health and Risk Management. 2016; 12, 477-80.

https://doi.org/10.2147/VHRM.S120944 